\title{
Article
}

\section{Adoption Barriers of IoT in Large Scale Pilots}

\author{
Ali Padyab ${ }^{1,2, *}$, Abdolrasoul Habibipour ${ }^{1}$, Aya Rizk ${ }^{1}$ and Anna Ståhlbröst ${ }^{1}$ \\ 1 Information Systems, Luleå University of Technology, Luleå 97187, Sweden; \\ abdolrasoul.habibipour@ltu.se (A.H.); aya.rizk@ltu.se (A.R.); anna.stahlbrost@ltu.se (A.S.) \\ 2 School of Informatics, University of Skövde, Skövde 54128, Sweden \\ * Correspondence: ali.padyab@his.se
}

Received: 9 December 2019; Accepted: 26 December 2019; Published: 29 December 2019

\begin{abstract}
The pervasive connectivity of devices enabled by Internet of Things (IoT) technologies is leading the way in various innovative services and applications. This increasing connectivity comes with its own complexity. Thus, large scale pilots (LSPs) are designed to develop, test and use IoT innovations in various domains in conditions very similar to their operational scalable setting. One of the key challenges facing the diffusion of such innovations within the course of an LSP is understanding the conditions in which their respective users decide to adopt them (or not). Accordingly, in this study we explore IoT adoption barriers in four LSPs in Europe from the following domains: smart cities, autonomous driving, wearables and smart agriculture and farming. By applying Roger's Diffusion of Innovation as a theoretical lens and using empirical data from workshops and expert interviews, we identify a set of common and domain specific adoption barriers. Our results reveal that trust, cost, perceived value, privacy and security are common concerns, yet shape differently across domains. In order to overcome various barriers, the relative advantage or value of using the innovation needs to be clearly communicated and related to the users' situational use; while this value can be economic in some domains, it is more hedonic in others. LSPs were particularly challenged in applying established strategies to overcome some of those barriers (e.g., co-creation with end-users) due to the immaturity of the technology as well as the scale of pilots. Accordingly, we reflect on the theoretical choice in the discussion as well as the implications of this study on research and practice. We conclude with providing practical recommendations to LSPs and avenues for future research.
\end{abstract}

Keywords: internet of things; adoption; end-user; innovation; barrier; large scale pilot

\section{Introduction}

The idea of enabling people and objects to be connected through the Internet infrastructure has given birth to a stream of research known as Internet of Things (IoT). Gubbi et al. [1] defined the IoT as "the worldwide network of interconnected objects uniquely addressable based on standard communication protocols" (p. 1647). Since the idea was proposed at the first Cyberspace Conference in 1990, huge investments have been put into IoT and both academics and practitioners have introduced many innovative services and applications. One of these ambitious investments is the IoT European Large-Scale Pilots (LSPs) program that is aimed to foster the deployment and evolution of IoT solutions with a total funding budget of $€ 100 \mathrm{M}$. This means that IoT technologies are steadily progressing and has reached a stage where IoT is mature enough for the development, testing and integration activities on a societal level [2] such as an LSP.

The determinants of users' adoption remain a necessary role in investigating the implementation of IoT in various domains. The IoT devices have various interactive capabilities such as but not limited to, the interconnectivity with other devices, things, environments and people. In this regard, some 
services provided via IoT are dependent on the human factor as part of data gathering and receiving the services. Accordingly, IoT involves individuals much more deeply with the technology in ways that go far beyond content creation and sharing for example, Web 2.0 [3]. Among various users of IoT, end-users are one of the ultimate beneficiaries and at the center of everything [4] and IoT's full potentials depends on end-user adoption and acceptance [4,5].

In Information Systems Development (ISD), a sustainable user engagement is a key factor for the successful IT artefact development [6]. A pilot is considered as the last stage of the test and evaluation of an ISD. To increase the level of acceptance and adoption of the technology being developed in a project, it is important to understand what motivates end-users to use IoT technology and to contribute with their insights and experiences of using IoT in the LSPs. Moreover, participants in an LSP, could be considered as a potential adopter when the innovation is released. To date, IoT innovation adoption literature is technology focused and is based on factors affecting adoption whereas the process of adoption is lacking [7]. Most research has taken the elements of the adoption and acceptance theories $[8,9]$ and treats them as factors affecting the adoption that is, focused on innovation adoption determinants. Moreover, there is an lack of understanding of experts and beneficiaries' perspectives on innovations which is reflected in IoT adoption research being mainly devoted to the organizational perspective rather than the individual adoption of end-users $[10,11]$. Moreover, the process of end-user adoption of IoT within an LSP can be considered as a new phenomenon, thus it is currently a rather under researched area.

An LSP is a good opportunity for the IoT developers to implement and test their IoT solutions and to attract potential future adopters. While there are factors that related to IoT artefact which facilitates (or hinders) its adoption (adoption determinants), the process of IoT adoption needs careful scrutiny as well. This study therefore set out to: 1 . Systematically review the factors affecting end-user adoption of IoT and 2. To investigate end-user IoT adoption challenges and constituent barriers within LSPs from a process perspective. To address the above-mentioned gaps, we conducted a literature review, ran two workshops and conducted 10 interviews with four IoT LSPs in Europe in order to determine relevant adoption barriers that end-users might face. The results indicate that an IoT LSP is a complex ecosystem and the process of its adoption can't be fully explained via traditional sequential approaches. Drawing on the findings of the interviews, we propose suggestions on aspects that are considered relevant for adoption of IoT solutions in the course of an LSP. We believe that this article proposes some new and valuable insights to researchers and practitioners to characterize and address the challenges of end-user adoption of use of IoT in their intended LSPs.

The article is structured as follows. In Section 2 we review the related work in the literature, followed by theoretical framework in Section 3. Section 4 presents the research design of the study and Section 5 presents the results of our interviews. Section 6 discusses the theoretical and practical contributions of the study and concludes the paper by proposing some recommendations.

\section{Literature Review}

When testing innovative solutions together with its intended end-users in their real-life context, is defined as pilots, field tests or field trials. In a pilot, a process consisting of multiple stages is applied. These stages are usually need finding, requirement analysis, technology integration, and, test and evaluation corresponding to the phases of the human-centered design for interactive systems approach [12]. There are several reasons for carrying out pilots, some are more related to democratic aspects such as the end-users right to have an impact about things directly influencing their everyday life, to balance power relations between different competencies and objectives and also to gain deep understanding into end-users needs and motivations to design solutions that creates value for them. Other reasons are more related to the innovation as such where the pilot will provide feedback on the design and how it is used in its real context, here unexpected use situation might emerge and thus offering opportunities for exploiting the innovation, the relevant stakeholders are involved in the process which foster innovation and prepare for a wider IoT adoption and finally the impact of the 
technology intervention on individual and socio-economic level can be assessed [13]. In recent years, a shift towards a new piloting paradigm, Large Scale Pilots (ISPs) has emerged challenging traditional piloting which is usually conducted on a small scale.

Currently, the research concerning pilots within IoT deployments have emphasized the planning of the pilots as well as the challenges associated to the implementation phase in a pilot study. The challenges that has been identified are categorized based on the issues related to the technology, data management, social, privacy, security, ecological, ethical, standardization, policy and business models underlying the services [14]. It is also important that the technological set up grapples with issues concerning interoperability, connectivity, data processing power, clear data governance and available resources (e.g., software and hardware components) [13,15]. Friess and Riemenschneider [16] (p.10) have noted that the notion of LSPs needs to be broader than focusing only on validating technological approaches from a scalability and operational perspective but also to evaluate user experiences and reactions to IoT solutions. Hence, the IoT European Research Cluster (IERC) view end-user involvement in LSPs as essential [17].

End-users can contribute to the LSPs in many different ways by providing data, validate the deployed structure, test the IoT solution, give insights on their experience from using the technology and its potential social impact, give feedback on improvements and feedback on software solutions [18,19]. But this is not enough; when users are involved in LSPs, a focus primarily on technological issues becomes too narrow. In pilots engaging end-users, issues related to social and ethical aspects becomes more apparent which for example, can be seen in the analysis of one deployment site of a smart living LSP by Fico et al. [20]. In their study of engaged end-users in the LSP, aspects related to privacy, security, safety (falls and monitoring health), social engagement (keeping contact with social networks), transport, mobility and leisure (serious games) became important aspects to address in the LSP [20]. From a pilot management perspective, all these challenges including end-user engagement, IoT governance, security, privacy and trust are important policy issues that need to be handled in LSPs [17], hence a broad range of expertise and competences to successfully implement the LSP are required [21]. In LSP processes it is important to not only understand how and why end-users should be involved in the pilots, but it is also important to understand what makes end-users adopt or reject technological solutions tested in LSPs. To date, there has been little attention been paid to the barriers related to end-users' adoption in relation to the process of an IoT LSP.

Technology adoption can, according to Khasawneh [22], be defined as the first use or acceptance of a new technology or new product. This process can be influenced by many factors [23], characterized by innovation, organizational, individual and environmental determinants [11,24]. Innovation adoption related to IoT solutions has been discussed from an organization or industry's point of view [7], while there exists relatively few attempts to understand acceptance of IoT technologies from the perspective of individuals [e.g., 5], they have employed dispositional measures such as trust, usefulness, ease of use and social influence which are insufficient to capture all relevant dimensions of user concerns in the IoT context [25]. Additionally, dispositional factors are innate and involve individuals' overall concerns, whereas contextual factors (e.g., LSP) are situation-specific conditioned by the context of the information exchange [26]. In this section, through the systematic literature review, we aim at investigating factors that are important for the adoption of IoT in the context of an LSP.

Lu et al. [7] synthesis IoT applications in 14 service domains, by categorizing them into four types according to their target and scope of adoption, namely, infrastructural level (e.g., smart city), organizational level (e.g., smart agriculture), individual level (e.g., wearables) and all-Inclusive level (e.g., self-driving cars). While reviewing adoption barriers in all 14 service domains is not within the scope of this paper, we have selected one or two services representing each of the IoT application levels. The next section presents in more detail the inhibitors of end-user adoption in four application levels of IoT.

To address the first aim of this study, we followed a concept centric literature review approach as outlined by Webster and Watson [27]. This approach is in contrast to the author centric approach 
in which the readers are usually familiar with the main topic and there are already available studies that discussed the main topic in detail. However, when it comes to the IoT LSPs, to the best of our knowledge, there are few such studies focusing on these topics as the nature of IoT LSPs are relatively emerging concepts.

Accordingly, the literature review process was started by identifying the core journals and conferences in each of the four levels (in which representing one IoT application domain). We then went through the table of contents of each of these core journals and conferences and manually searched for the relevant articles by reviewing the title, abstract and keywords of the articles. In addition to the core journals, we searched for the articles in three online databases (namely, Google Scholar, Scopus and Web of Science), for each of the main four levels and the key terms for literature search were customized accordingly. The literature review process was repeated four times for each of the four levels.

Finally, in order to identify further relevant studies, backward and forward citation analysis based on Webster and Watson's [27] recommendation were conducted. We employed this approach because the number of relevant findings in the previous steps was too few to obtain reliable results. Only publications in English language were considered in this review. Due to emerging nature of IoT, no time limitation was set in this review. Table 1 shows an overview of the main search terms that used for conducting the literature review

Table 1. Overview of the search terms.

\begin{tabular}{|c|c|c|}
\hline Application Scope & Domain(s) & Search Term (ST) \\
\hline Infrastructural level & Smart city & $\begin{array}{l}\text { ST1: “IoT" AND “Smart City" AND “Adoption" } \\
\text { ST2: “IoT" AND “Smart Cities" AND “Adoption" }\end{array}$ \\
\hline Organizational level & Smart agriculture and farming & $\begin{array}{l}\text { ST1: "IoT" AND “Farming" AND "Adoption" } \\
\text { ST2: "IoT" AND "Agriculture" AND “Adoption" }\end{array}$ \\
\hline Individual level & Wearables & $\begin{array}{l}\text { ST1: “IoT" AND “Wearables" AND "Adoption" } \\
\text { ST2: “IoT" AND "sensors" AND “Adoption" }\end{array}$ \\
\hline All-Inclusive level & Self-driving cars & $\begin{array}{l}\text { ST1: "IoT" AND “Autonomous car" AND “Adoption" } \\
\text { ST2: "IoT" AND "self-driving car" AND "Adoption" }\end{array}$ \\
\hline
\end{tabular}

\subsection{Users Adoption Barriers in Various IoT Application Levels}

\subsubsection{Infrastructural Domain: Smart Cities}

The IoT technology provides, in a way, an infrastructure for objects to be connected creating a network that resembles a smart environment. Such networks may represent buildings, waste management systems, energy grids or whole cities. The role of the individual varies in these networks; they either act as service end-users who also "own" an IoT device-such as smart meters or as one who is affected by IoT devices indirectly-such as citizens benefiting from $\mathrm{CO}$ emissions monitoring using sensors. This limited and often indirect and hidden, interaction with IoT makes the end-users' adoption challenging in a different way, as compared to other domains. At best, end-users are able to assess the influence of IoT on their experience (i.e., city life); thus, the adoption barriers are mostly experiential.

Previous studies have shown that the individual's comprehension of the relative advantages of smart city technology, such as realizing the impact of IoT on the different city aspects, is a key factor in adopting related services [28]. An important precursor to assessing this impact is to be aware about the initiatives and services being offered in one's city. Accordingly, if the cities and service providers are not transparent with the services and their availability, citizens tend to be reluctant to be engaged $[29,30]$. Being aware about the smart city technologies, end-users can gauge if the technology is feasible to adopt [30], if it is cost effective [28] and if it is compatible with their lifestyle [29]. IoT is regarded to be compatible in case it requires no to minimal change from the end-user (e.g., learning new skills). Lytras and Visvizi [29] suggest that soft skills and ICT skills are required by citizens to interact with the services, making it one factor hindering the adoption of smart city.

Complexity is also relevant here since various groups of end-users are engaged in the implementation process. Their participation could be affected if they experience difficulties, especially 
if they compare it to traditional services or other more mature IoT services. In this regard, usability, ease of use and UX aspects are important factors to minimize complexity [30].

In addition, the security of IoT technologies represent a main concern for end-users, comprised of vulnerabilities, third party access to the devices and availability of the services-particularly in the cases of disaster/incident management and emergency response [25,31]. The level of devices' security indicates that malevolent acts by hackers or foreign governments are not successful, for example, penetrating devices and using the infrastructure as a weapon of mass surveillance. This relates to the next main concern over IoT in smart cities: privacy.

Many researchers and practitioners noted privacy as a key construct increasing the adoption of an innovation. Factors related to privacy include awareness related to the collection of data and use of services, especially big data services where the concern of personal data protection is significant [29]. Privacy has implications on two other important adoption barriers: service quality and trust. It is suggested in the literature that the poor quality of smart city infrastructure limits the added value and perception of smart city services [32]. Citizen trust in the services provided within the IoT domain is another influencing factor to handle the risks, threats and opportunities. Trust is both related to the information handling practices of IoT manufacturers, as well as those of service providers [25]. Compared to security and privacy, ethical concerns are found to have a minimal effect on the smart city service adoption [29].

\subsubsection{Individual Domain: Wearables}

Factors influencing the adoption of innovations with wearable sensors can be broadly categorized into general, physical and software characteristics. The general factors presented in the literature include the high price associated with emerging technology [33], culture and gender for specific wearables [34], social influence [35] and personal preferences [36,37].

Physical design and characteristics could also influence adoption and diffusion of wearables. When wearables were introduced in the 1990s, wearability was among the first design principles to be defined. It refers to the user appeal regarding the physical situation of the device in a way that the user and others, consider it as part of the user [38]. Another necessary physical characteristic is the device's mobility, that is, not being heavy. Users need to have access to the information anywhere with the ability to move to different locations and use their devices in transit [39]. In the same vein, comfort is an important requirement for adoption, where the user does not feel extra burden when wearing the device. Uncomfortable wearables can inflict health risks on the user, such as bruise, burn marks and rashes [40]. One study confirms that there is a negative impact of perceived health risk on the user's behavioral intention to use smart glasses due to health concerns related to radiation emitted very close to the brain [41].

Additionally, the physical and aesthetics design aspects of a wearable device can create a form of stigma, in a sense that the user might feel ashamed because others interpret the usage of the device as a sign of weakness or illness, resulting in worsened social image [42]. A similar study on smart watches suggests that the design (e.g., shape, material and color) of smart watches to be most important to users' adoption [43]. Moreover, users' environmental situations vary greatly and the device may be exposed to extreme temperatures, shock and/or contact with water and dust. Thus, ruggedness of the device plays an important role to make sure that the device can operate in normal conditions and even sometimes on harsh conditions [42]. Another frequent concern reported in the literature is the wearable's battery. Cain [44] mentions battery life as a key challenge in wearables due to their design restrictions - they are moveable, sometimes small and thin, it leaves little space compromising the battery capacity. Last on the physical characteristics, sensory errors, represented by inaccurate or missing measurements, is another factor that could have a negative impact on users' adoption.

Characteristics related to the software and the digital service associated with the device greatly impact the adoption of wearables. Users' perceived value of the innovation in the real world is one of the prominent factors that is well understood in the domain of wearables. User should be able to 
clearly realize the advantages of wearable compared to other devices or services delivering the same function [45]. The perceived value is connected to the ease of use and functional elements. Adapa, Nah, Hall, Siau, and Smith [46] suggest that a well-designed interface promotes the ease of use and Pustiek et al. [42] suggest that user interfaces for wearables is a vital design factor to achieve greater user experience. User interfaces are related to presentation of useful, accurate and valid information to the user. Simultaneously, the interface design should avoid over burdening the user's cognitive functions by, for instance using complicated language or lack of context. These adoption barriers could be alleviated with the design of a user-friendly interface.

Moreover, functional elements such as integration with other devices, portability of the data and supporting software are relevant to the services of the wearables. Similar to infrastructural domains, data collected via wearables are subject to privacy and security risks, especially in the field of health wearables owing to the sensitivity of the collected data [47]. Usage ban has been proposed for some wearables (e.g., smart glasses) in some places, such as in movie theaters to avoid movie piracy or in changing rooms to avoid illegal filming. These are some reasons that users could not wear the devices all times, influencing their adoption [48].

\subsubsection{All-Inclusive Domain: Autonomous Driving}

The current discourse on autonomous driving suggests that trust remains to be the number one barrier to its acceptance, adoption and continued use [49,50]. This lack of trust and skepticism are related to the perception of passenger safety and uncertainties regarding its use. End-users' trustworthiness towards autonomous vehicles are related to different characteristics of an autonomous vehicle such as deceleration, acceleration, different types of turns (T-junction, U-Turn) and steering. Trust issues are typically associated with emergent technologies, particularly when it represents a big leap, leaving prospective users with little control over for example, steering, throttle or braking without their direct input [51].

Individuals' beliefs and general attitudes towards autonomous driving can also shape their decisions about whether to use an autonomous vehicle or not. Data and information security aspects affect these negative attitudes, manifesting in fear that an autonomous vehicle, just like other IT devices, will not be entirely secure and that data may be misused [52]. Privacy infringement and personal data misuse are main consequences the users fear. Other subjective and personal preferences increase the adoption barrier towards autonomous vehicles, when compared with personal and traditional cars, such as the hedonic value of the driving experience (i.e., fun of driving), control and sense of freedom [52,53].

While trust is voiced in the end-user focused literature, another factor remains as critical to innovation adoption; that is being aware of the innovation. According to Fraedrich and Lenz [52], $44 \%$ of respondents indicated they knew nothing about the subject, which clearly shows that awareness of it is far from penetrating all corners of society. Zmud and Sener [53] (p. 2518) suggest a complementary aspect of awareness, noting that "while respondents were aware of the concept of self-driving vehicles, they were not very knowledgeable of them ... general public is not yet familiar with the new opportunities (or challenges) self-driving vehicles may bring, such as within household car-sharing, new types of car-sharing fleets or the challenges of mixed fleets on the road."

This lack of awareness, in its general terms, includes the lack of knowledge on how litigation and liability work with autonomous vehicles. The public have their doubts and uncertainties, rightly so, regarding regulatory agency, insurance and liability issues arising, including persuading insurance providers that the technology will work properly, in all driving environments [54]. Concerns evolve around for example who is responsible in case of an accident and how fully autonomous vehicle users might be held accountable [52].

Total cost of ownership or service is also still unclear in this domain, influencing adoption. Costs associated with self-driving cars are related to the ownership, maintenance, fuel and tolls $[54,55]$. 
Google is tackling this issue currently by deploying various machine learning models for cost learning and estimation [56-58].

\subsubsection{Organizational Domain: Smart Agriculture and Farming}

On the organizational level, IoT is used to manage resources across various lines or verticals within the organization, as well as across the food value chain. In smart agriculture, sensors are used for verticals such as water management, crop management, soil moisture and $\mathrm{pH}$ measurement, while in smart farming, livestock management represents a key vertical [59]. While each of these verticals has its specific adoption barriers, most barriers in the literature are cross cutting the whole industry. Jayashankar et al. [60] suggest that trusting the technology provider is also the main influencing factor on adoption, mediated by the perceived value of the IoT solution and perceived risk associated with it. They further define the perceived value into economic, environmental and epistemic value. In addition to trusting technology providers, trusting supply chain partners using a specific IoT technology is a determinant factor in the process of adoption [61].

Lack of technical knowledge among farmers is regarded as an important factor in challenged adoption $[59,61]$. This factor becomes more challenging in rural areas within developing countries where there is lack of education and awareness of technology [62]. A lack of literacy adds an additional complexity to using IoT technology in farming (ibid). On the other hand, Lin et al. [63] argue that the employees' resistance to new technology does not influence adoption; instead, the size of the organization and complexity of the technology are the most determinant factors in adoption.

Specific technical characteristics also influence the adoption of IoT in agriculture and farming. For instance, the common centralized architecture of IoT platforms creates bottlenecks causing delays in communication [59]. While this may not be critical in most applications, some applications require real-time data collection and analysis that may be hindered by such bottlenecks. Centralized architectures are also a main barrier towards scaling. Others suggested that explicitly accounting for weather-related power and internet outages in IoT platforms design lowers adoption barriers and prolongs deployment periods $[64,65]$. On the hardware side, battery capacity, lifetime and sensor storage capacity are among the challenges affecting adoption [59]. The cost of these units and overall IoT services are also influential [61,62].

There are also infrastructural factors influencing adoption: (a) technical infrastructure factors such as the stability of internet connections in agricultural, rural and farming areas [62] and (b) political infrastructure factors such as governmental support for IoT projects [61]. Finally, like any industry, agriculture and farming are subject to external pressures. More specifically, dietary trends at the consumer end have major impact on how the industry operates and the technology adoption decisions [66].

A summary view based on the most literature review in the four application levels of IoT is presented in Table 3. These adoption barriers impose potential challenges in general, which have implications during an IoT LSP. In the remaining of the paper we discuss in more detail, the process of IoT adoption and its constituent barriers within LSPs.

Table 2. Summary of adoption barriers at four application levels of internet of things (IoT).

\begin{tabular}{|c|c|c|c|c|}
\hline Adoption Barrier & $\begin{array}{c}\text { Infrastructural } \\
\text { Level }\end{array}$ & $\begin{array}{c}\text { Individual } \\
\text { Level }\end{array}$ & $\begin{array}{c}\text { Organizational } \\
\text { Level }\end{array}$ & $\begin{array}{c}\text { All-Inclusive } \\
\text { Level }\end{array}$ \\
\hline Lack of awareness and knowledge & * & & * & * \\
\hline Unclear advantage (perceived value) & * & * & * & \\
\hline Compatibility (with existing solutions) & * & * & & \\
\hline Complexity & * & * & & * \\
\hline Usability issues & * & & & \\
\hline High skills requirements (lack of technical knowledge) & * & & * & * \\
\hline Data security & * & * & & * \\
\hline Privacy concerns (including secondary use of data, storage, etc.) & * & * & & * \\
\hline
\end{tabular}


Table 2. Cont.

Table 3. Summary of adoption barriers at four application levels of internet of things (IoT).

\begin{tabular}{|c|c|c|c|c|}
\hline Adoption Barrier & $\begin{array}{l}\text { Infrastructural } \\
\text { Level }\end{array}$ & $\begin{array}{l}\text { Individual } \\
\text { Level }\end{array}$ & $\begin{array}{l}\text { Organizational } \\
\text { Level }\end{array}$ & $\begin{array}{l}\text { All-Inclusive } \\
\text { Level }\end{array}$ \\
\hline Transparency of provided services & * & & & \\
\hline Lack of trust (on the IoT solution and service providers) & * & & * & * \\
\hline Inappropriate physical design (including mobility) & & * & & \\
\hline Comfort & & * & & \\
\hline Perceived risks & & * & * & \\
\hline Ruggedness of the IoT device & & * & & \\
\hline Low battery capacity and lifetime & & * & * & * \\
\hline Inaccurate measurement & & * & & \\
\hline Unfriendly user interface & * & * & & \\
\hline Data portability issues & & * & & \\
\hline High cost & * & * & * & * \\
\hline Hedonic value & & & & * \\
\hline Physical safety & & & & * \\
\hline $\begin{array}{c}\text { Technology skepticism (negative attitudes towards IoT } \\
\text { technologies) }\end{array}$ & & * & & * \\
\hline Immature IoT technology & & & & * \\
\hline Legal and regulatory issues & & * & * & * \\
\hline Stigma and social influence & & * & & \\
\hline Lack of education & & & * & \\
\hline Limited communication between IoT devices & * & & * & \\
\hline Centralized architectures & & & * & \\
\hline $\begin{array}{c}\text { Technical infrastructural issues (e.g., instability of internet } \\
\text { connections) }\end{array}$ & & * & * & \\
\hline Institutional influence (in case of professional user) & & & $*$ & \\
\hline
\end{tabular}

*: The barrier is relevant for the application level of IoT.

\section{Theoretical Framework}

In this study, diffusion of innovation theory (DOI) [9] has been used to guide the data collection and analysis process. Diffusion of innovation theory is a widely accepted theory to explain technology adoption over time [67]. According to Rogers, there are five steps for adoption of innovations namely, knowledge, persuasion, decision, implementation and confirmation. Based on these five steps, innovation adoption can be defined as:

"the process through which an individual or other decision-making association passes from first knowledge of innovation, to forming an attitude towards innovation, to a decision to adopt or reject, to implementation of new idea and to confirmation of this decision." [9] (p. 11).

Knowledge occurs when a potential end-user learns about the existence on the innovation and gains some understanding of how it is functions. Persuasion occurs when a potential end-user forms a favorable or unfavorable attitude towards the innovation and is open to being persuaded that the innovation holds value (show interest). Decision occurs when a potential end-user undertakes activities, which lead to the adoption or rejection of the IoT solution (mental trial). Implementation occurs when the innovation is used or practiced (is tested by end-user in a limited basis). Finally, Confirmation occurs when an end-user seeks support for the adoption decision in the form of confirmation that the decision was a correct one (the user may also reverse this previous decision if exposed to conflicting messages about the innovation).

The DOI theory is useful to unravel the progress of technology adoption within IoT field. For example, previous research has found that IoT has arrived at the implementation stage and IoT technology adoption is occurring at the level of the whole society rather than that of individual units [2]. The implication for the evolution of IoT is that its test and evaluation can now be integrated on a wider scope (LSP) than before, with its real-life end-users rather than just test users. In the innovation literature, the DOI researchers have sought to explain individual adoption decisions or intentions to adopt. However, some scholars have enumerated some threats of DOI, if used to explain the diffusion of complex and networked systems [68]. Such threats are because technologies are not discrete packages, variations in the institutional scopes and mandates, the diffusion rate is not solely a function of push 
and pull forces and the diffusion rate between industry sectors are highly interdependent (ibid). In this paper, we argue that an LSP could be considered as a complex system but at the same time there are many units of adoption such as individuals, groups, teams or departments [69].The combination of two (i.e., adoption of individuals in a complex system) is a challenge that the research so far has not accounted for in the case of LSPs.

DOI is a suitable candidate for understanding the interaction between the context and technology and offers some advantages in this study. First, in the current study, DOI was utilized to investigate how technology affects the choices made by the end-users and how end-user choice influenced IoT in an LSP. Second, it will enable us to organize and extend the discussion in relation to the different steps of adoption of IoT technologies. The innovation adoption barriers can be related to all phases of adoption process from knowledge phase (e.g., poor dissemination of information about the innovation, lack of education, etc.) to the final confirmation stage (e.g., expensiveness of digital innovation for end-users). Third, to alleviate the threats of adopting DOI in the complex systems, we sought recommendations provided by Lyytinen and Damsgaard [68] to investigate all key players in the diffusion arena, the patterns of adoption and the critical process features.

\section{Methodology}

\subsection{Workshops}

In the first phase, we designed the study based on the theoretical framework, resulting in an outline for a conducting two workshops. The initial workshop protocol was structured according to the five phases of theory of diffusion of innovation [9], as indicated above. The first workshop conducted with nine participants during the June 2018 at the IoT week event in Bilbao, Spain. All participants were experts in the field of IoT development and participated on behalf of nine different companies. The workshop was focused on two objectives-(1) identify and discuss end-users adoption barriers related to IoT implementations and (2) to identify potential enablers for adoption. Further, the participants were divided into two groups to come up with adoption barriers, share and discuss their ideas with each other. The groups documented their findings on the Post-it notes. The workshop lasted for 1 hour and 45 minutes. At the end, a summary report was prepared based on the Post-it notes.

The second workshop was held in December 2018 at the ICT2018 conference in Vienna, Austria. The workshop was open to everyone who attended the conference and after several reach-out attempts (via Twitter and LinkedIn), eleven experts joined the workshop. The focus of the workshop was on European IoT LSPs' representatives that are actively working to engage end-users in their projects. During the workshop, we followed an interactive approach that enabled participants to share their end-user engagement experiences by means of a Post-it session. The workshop took about 45 minutes and it was audio recorded.

The two workshops followed the same procedure. First, the sessions started by discussing about the experiences of the participant with respect to the pains and gains that arise when adopting IoT in LSP projects. The discussion that was facilitated by a reverse brainstorming approach (what do we have to do to completely disable IoT?) to generate as many potential barriers as possible in an informal and creative way. After gathering the barriers and clustering them, from the clusters, IoT adoption barriers were identified and the most prominent barriers were selected. After this, an adoption barrier was discussed in each table to identify and co-create solutions for each of the five IoT-LSPs. Finally, the session concluded by sharing insights of different tables and reflecting on the results from all tables. The workshops allowed us to ensure that the later stages of the investigation would capture the point of view of the informants.

\subsection{Case Studies}

Case study makes a suitable approach for this research for many reasons. A case study is an investigation of a phenomenon to understand the dynamics involved in a real-life setting where there 
is no evident boundary between the phenomenon and its context and multiple sources of evidence are used [70,71]. Moreover, we sought to understand contextual details and depth of experience in the LSPs in relation to end-users' IoT use. For this reason, we investigated four IoT LSPs that were running during the period of this study in Europe. The main empirical materials for the case studies were interviews with pilot experts and secondary data by means of project reports. Interview is distinguished qualitative data collection method that allows the researchers to capture such complex phenomena and experiences from the narratives of the participants [72]. A semi-structured interview protocol was developed based on the insights gathered in the workshops. The protocol aimed to develop a holistic view of the end-users' role during the pilot implementation and what experts deem as actual and potential adoption barriers they have experienced in the pilots. Roger's theory of DOI outlined the themes of the interview.

In addition to the interviews, secondary data in the form of project reports was used to provide our analysis with strong contextual grounding. The selected reports comprised of specifics about pilots such as use cases, end-user requirement analysis, pilot deployment process, end-user adoption and acceptance, impact assessment and KPIs. In total, 12 deliverables were analyzed. All four projects started in 2017 and funded by the European Commission in the context of Horizon 2020 scheme. The description of the projects that we studied as our case of IoT LSP were (Due to space limitations, we refer the readers to learn more about the projects on: https://european-iot-pilots.eu/):

- SynchroniCity-The aim of SynchroniCity is to establish a global IoT marketplace where cities and businesses create and trade common digital services to improve the lives of citizens and grow local economies in Europe. The project is focused on how to incentivize and build trust for companies and citizens to actively participate and find common co-created IoT solutions for cities that meet citizen needs and to create an environment of evidence-based solutions that can easily be replicated in other regions.

- MONICA (Management of Networked IoT Wearables-Very Large Scale Demonstration of Cultural and Security Applications) has the aim to demonstrate how cities can use existing and new IoT solutions to meet sound, noise and security challenges at big open-air events in order to handle emerging incidents which attract and affect many people, like those who enjoy the music and those who live close to the events and want to have the noise mitigated. The eleven pilots in the six cities Copenhagen, Bonn, Hamburg, Leeds, Lyon and Torino, will involve more than 100,000 end-users in total.

- AUTOPILOT (Automated driving Progressed by Internet of Things) is to develop a range of driving services, to address urbanization challenges which take advantage of the potential of IoT to improve automated driving. The project aims to test the autonomous cars in real conditions, at six large-scale sites, which are focused in four different automated driving use cases-valet parking, highway use, platooning and urban driving. In each case, the users are considered either as a driver or a passenger.

- IoF2020 (Internet of Food and Farm 2020) aims to utilize IoT technology to the agri-food sector, in order to ultimately increase the sustainability by addressing environmental and social challenges through fostering a large-scale uptake of IoT in the European farming and food domain. The project conducts 5 trials with a total of 19 use cases in arable, dairy, fruits, vegetables and meat production. The end-users that we focused for this project were farmers, due to the familiarity of the experts that we interviewed for this domain.

In total, 9 experts were selected for the interviews, drawn from pilots that across full range of IoT application levels [7]. Because several of the participants preferred anonymity, we will present all participants and their organizations anonymously. All interviews were conducted via a teleconferencing tool called Zoom, recorded and transcribed verbatim. Details about the participants' experience, role, service domain and project are given in Table 4 and the data collection details of the study are given in Table 5. The list of interview questions is shown in the Appendix A. 
Table 4. Participants' experience, role and workplace and project.

\begin{tabular}{|c|c|c|c|c|}
\hline Participant (ID) & Experience & Role & Service Domain & Project \\
\hline Expert (1) & $\begin{array}{l}+7 \text { years in project } \\
\text { management }\end{array}$ & $\begin{array}{l}\text { User requirements } \\
\text { analyst }\end{array}$ & Self-driving Cars & AUTOPILOT \\
\hline Expert (2) & $\begin{array}{c}+17 \text { years in research and } \\
\text { development }\end{array}$ & $\begin{array}{l}\text { Development and } \\
\text { Integration of IoT }\end{array}$ & Self-driving Cars & AUTOPILOT \\
\hline Expert (3) & $\begin{array}{c}+14 \text { years in business } \\
\text { development }\end{array}$ & Field test expert & Smart Agriculture & IOF2020 \\
\hline Expert (4) & $\begin{array}{c}+19 \text { years in agricultural } \\
\text { engineering }\end{array}$ & $\begin{array}{l}\text { Development and } \\
\text { integration }\end{array}$ & Smart Agriculture & IOF2020 \\
\hline Expert (5) & $\begin{array}{c}+14 \text { years in project } \\
\text { management }\end{array}$ & $\begin{array}{c}\text { Pilots validation and } \\
\text { evaluation }\end{array}$ & Wearables & MONICA \\
\hline Expert (6) & $\begin{array}{c}+16 \text { years in management of } \\
\text { product development }\end{array}$ & $\begin{array}{l}\text { End-user test and } \\
\text { evaluation }\end{array}$ & Wearables & MONICA \\
\hline Expert (7) & $\begin{array}{l}+7 \text { years in management of } \\
\text { urban sound environment }\end{array}$ & Researcher & Wearables & MONICA \\
\hline Expert (8) & $\begin{array}{l}+6 \text { years in management of } \\
\text { urban sound environment }\end{array}$ & Researcher & Wearables & MONICA \\
\hline Expert (9) & $\begin{array}{l}+13 \text { years in research and } \\
\text { innovation within smart city }\end{array}$ & $\begin{array}{l}\text { Data integration and } \\
\text { policy development }\end{array}$ & Smart City & Synchronicity \\
\hline
\end{tabular}

Table 5. Summary of data collection.

\begin{tabular}{|c|c|c|c|}
\hline Data Collection Method & Participant (ID) & Date & Empirical Material \\
\hline Workshop \#1 & Experts (WS1-1/9) & June 2018 & Notes-Post-it \\
\hline Workshop \#2 & Experts (WS2-1/11) & December 2018 & Notes-Post-it \\
\hline Interview & Expert (1) & March 2019 & $\begin{array}{l}\text { Audio recording-Verbatim } \\
\text { transcript-Interview notes }\end{array}$ \\
\hline Interview & Expert (2) & March 2019 & $\begin{array}{l}\text { Audio recording-Verbatim } \\
\text { transcript-Meeting notes }\end{array}$ \\
\hline Interview & Expert (3) & April 2019 & $\begin{array}{l}\text { Audio recording-Verbatim } \\
\text { transcript-Meeting notes }\end{array}$ \\
\hline Interview & Expert (4) & April 2019 & $\begin{array}{l}\text { Audio recording-Verbatim } \\
\text { transcript-Interview notes }\end{array}$ \\
\hline Interview & Expert (5) & March 2019 & $\begin{array}{l}\text { Audio recording-Verbatim } \\
\text { transcript-Interview notes }\end{array}$ \\
\hline Interview & Expert (6) & March 2019 & $\begin{array}{l}\text { Audio recording-Verbatim } \\
\text { transcript-Interview notes }\end{array}$ \\
\hline Interview & Expert (7) & April 2019 & $\begin{array}{l}\text { Audio recording-Verbatim } \\
\text { transcript-Interview notes }\end{array}$ \\
\hline Interview & Expert (8) & April 2019 & $\begin{array}{l}\text { Audio recording-Verbatim } \\
\text { transcript-Interview notes }\end{array}$ \\
\hline Interview & Expert (9) & April 2019 & $\begin{array}{l}\text { Audio recording-Verbatim } \\
\text { transcript-Interview notes }\end{array}$ \\
\hline Secondary Data & & March-May 2019 & 12 project reports in total \\
\hline
\end{tabular}

\subsection{Data Analysis}

All authors were involved with the data analysis via participating full-day sessions. The process of analysis was carried out in several steps following the principles outlined by Mayring [73]. This process includes open coding and creating categories iteratively. First, the authors read through the workshop notes and interview transcripts to gain an initial understanding of the contents. Because there is a risk for the researcher to neglect important aspects of naturally occurring speech when transcribing and loose the context of the narrative, the original audio recordings of the interviews were analyzed in parallel [74]. DOI was used as an analysis framework with respect to the LSP's adoption and diffusion process and end-users' relation to the process. Second, all authors started to code the first interview by delineating adoption as a process through DOI and applying codes to every passage of the transcript. Each code was compared to the previous codes and in case of association with other, higher order categories were created. After this, the authors attended their first meeting to discuss and 
reach a shared meaning of the content material. Upon initial agreement with the codes, the rest of the interviews were analyzed and discussed through 4 discussion sessions, each taking approximately 2 hours, to ensure the credibility of the findings [75]. During each discussion session, the authors compared their extracted codes and categories with each other, refining the themes using an iterative process. Finally, a saturation was reached at the point where we could not find new information from the content [76].

\section{Results}

Results from workshops and interviews show that experts face some barriers during each phase of innovation adoption and diffusion. Below, the barriers in each phase are presented.

\subsection{Knowledge}

One of the barriers for the LSPs was to articulate strategies to make their users aware about their innovation. While common channels such as websites and social media is widely used, some LSPs did not find online promotions enough and had to take more engaging approaches such as face to face outreach, physical briefings, show cases and on-site demonstrations. The reason for direct interaction with potential users were due to the nature of the IoT artefact and its associated services in an LSP in which in return shaped the strategies to interact with end-users. For example, in case of self-driving cars, there were concerns with privacy, safety and trust in the innovation which made AUTOPILOT pilot opting for experimentation by the users to alleviate their concerns and to build a trust in the technology.

"For me the most important thing [regarding knowledge] is to communicate to users, how their data is used ... the other important thing is to users get in touch with the technology to experience it themselves, it is not sufficient to just have an online promotion." (Expert 1 )

On the other hand, direct interaction may itself become a barrier due to logistical complexity in providing the associated experience. In the MONICA LSP, event organizers were concerned that the distribution and collection of the wearables would disturb the end-user's experience of the event.

"When you work with wearables, you have to distribute them and collect them at the end of the test or the festival. So, the event organizers are afraid of the logistic problems that this distribution may cause. It is our responsibility [as an LSP] to provide them with turn-key solutions to take care of those problems" (Expert 7)

We found that LSPs formulate their innovation knowledge strategies with respect to various target groups. For example, the issue of elderly care was brought up by one participant that "the elderly should contacted physically because generally elderly like to have someone around to talk about their problem" (an expert in workshop 1), whereas in the MONICA LSP, the knowledge about the innovation was communicated via online channels because the target user group was mainly young adults going to the concerts and generally aware about the wearables and are accustomed to finding relevant information online. Moreover, overlooking certain individuals and groups during this phase is dangerous according to the experts. The results revealed that beyond potential end-users of the technology, there are certain individuals that indirectly could impact the technology adoption along the process. According to the LSPs, identifying relevant non-users has a strong connection to the persuasion phase. For example, in the MONICA project, the event organizers and their employees (who are also professional users) facilitate the knowledge transfer to the attendees (end-users), consequently affecting persuasion. Likewise, some participant in workshop 2 brought up the issue with the elderly adopting smart health care IoTs through communication with the health care personal and elderly's family.

\subsection{Persuation}

The persuasion phase is tightly coupled with the knowledge phase. While users receive some awareness, there are barriers that need to be tackled such as attitudes towards the technology. In the literature review section, it was evident that some attitudes are formed even before the technology awareness, which challenges the persuasion of potential users (factors such as trust, hedonic values 
and benefits gained). In this regard, during the workshops and the expert interviews, the participants expressed that awareness about the technology should be complemented with the benefits of using the innovation rather that the artefact itself, to help potential end-users' calculus about cost-effectiveness of the innovation. The lack of knowledge about the benefits gained (e.g., cost cutting) and finding viable business models via IoT installations was a challenge for the LSPs.

"It is not only about the knowledge of the technology but it's also about the knowledge about their [farmers] businesses ... for instance, if you come with a robot to a farmer and say the robot will do better fertilizing, there will be no farmer that directly [recognizes that] I am loosing too much money by doing uneven fertilizing and in a wrong way and I will have too much margin to win by the robot." (Expert 4)

Accordingly, the IoT solutions will be adopted by end-users when they see a clear value, benefit and return of investment (as explicitly mentioned and discussed by the second workshop participants) by using that technology. In addition to highlighting the economic value, different LSPs identified different persuasion strategies for their solutions such as highlighting the hedonic value from using a wearable in a concert or using an autonomous car, ensuring that there is no or minimal negative impact from using the IoT solution (i.e., on personal health or on the environment), and/or clearly addressing any privacy concerns that may emerge.

"On health ... if they think [the solution] there are electromagnetic waves that can be dangerous to [their] health, it can be a barrier" (Expert 7)

As such, in addition to the common channels for knowledge dissemination, different pilots identified scenarios in which they could try to persuade the end-users to try and use their respective solutions. We refer to these scenarios as interaction checkpoints. These checkpoints represent opportunities for the LSPs to introduce the IoT solution to the user. Examples for these checkpoints is providing the wearables for testing along with events' tickets, by the event gates, smart farming showcases or involving end-users in prototype testing while developing smart city applications. Interaction checkpoints expands our knowledge beyond organizational adoption of innovation by implying that knowledge and persuasion in an LSP can be interwoven since end-users' adoption behavior is not influenced by the institutional properties that leverages the diffusion of technology, rather in the case of a pilot, the organizers strive to disseminate knowledge and persuade their users at any available opportunity.

\subsection{Decision}

At this phase of the innovation adoption, various dispositional and contextual factors hinder the adoption process. Among the dispositional factors are the characteristics of those who participate in a pilot study. Some participants are generally open for testing new technologies and some groups are rather resisting to new changes incurred via technology implementation. Farmers were one of the groups of users in one pilot project that were generally trickier to convince due to the unfamiliarity with the technology. Related to smart agriculture, one expert mentioned, "Data should be easy to read... it will be naïve to assume that farmers will become data scientists or be able to perform pattern recognition on satellite images" (Expert 3), while in contrast to younger users in the MONICA project, "younger users are expected to be inclined to use the technology more ... they have power banks to avoid battery consumption" (Expert 5).

Some of the barriers brought up during the workshops and interviews were related to the context of the use which did not seem to have a consistent impact among the pilots. For example, while the concerns over privacy was prominent among users of smart city, wearables, self-driving cars and smart health, it was not a concern among the farmers during the pilot. However, both experts from the IoF2020 project stressed that privacy is a concern among famers in real life situations in contrast to the pilot studies. Therefore, one interesting finding was that some barriers have a changing nature and unpredictable before contextualized. Hence, expanding adoption barriers in a pilot to a real-life situation use and vice versa can be misleading. 
In respect to privacy and security concerns, in both workshops, the participants acknowledged that secondary use of personal data, data ownership and data leakage are amongst the main barriers that discourage end-users to use and adopt IoT technologies. Despite this, privacy concerns are intertwined with transparency issues (which itself is an adoption barrier in this phase), because people do not read the terms and conditions that might cause lack of transparency. For example, as in the case of wearable sensors, an expert stated:

"The users need to see the terms and conditions, so they know about the sensors, data usage, etc. ... but sometimes people don't read terms and conditions... That is something that we cannot do anything about that ... and it can be resulted in lack of transparency ... We also provide this information in the ethical deliverables." (Expert 5)

The maturity and widespread use of the technology also influence the decision to adopt and use the solution. It was also evident that different types of end-users had different degrees of autonomy over their decision. For instance, an end-user using the IoT solution in their professional capacity, such as the event organizers' staff in MONICA or city officials in SynchroniCity, had a different scope of decision making than a concert attendee using a wearable in their leisure time or an elder person using it for activity monitoring. The pilots also often focus more on their direct user, even if it is not the solution's end-user. Expert 9 (from SynchroniCity) articulates their approach towards these different users' adoption as follows:

"The most important user for us is the cities. In fact, IoT adoption depends on the ability of the cities to be convinced about the benefits of the technology and decide to put the budget that is needed to have these solutions in the cities. Then the citizens will follow."

\subsection{Implementation}

The practical aspect of technology is a common adoption barrier among all LSPs. In this phase, users get in touch with the technology and any disappointment in this regard was considered as a barrier for user adoption for the LSPs. For this reason, LSPs made mini pilots throughout their implementation activities in which the technology was tested with its technical reliability before tested by the users. These mini pilot tests enabled evaluation of positive and negative effects of the elements of the technology maturity. One dilemma in the all LSPs was the extent to which the technology maturity allowed the project consortium to open up their innovation, since the funding scheme (i.e., Horizon 2020) required high technology readiness levels. One expert in the MONICA LSP mentioned that "If it [technology] does not work and that could be because of poor Internet connection or whatever, people will become frustrated quickly." (Expert 5). Usability, ease of use, complexity and UX aspects are relevant for the adoption, however, such aspects should be tested and evaluated before the actual pilot in which is contradictory with the technology readiness.

The technological problems (functionality, usability, etc.) were amongst the most challenging adoption barriers in both conducted workshops when they were asked to identify the most challenging barriers for IoT technologies to be adopted by end-users. As another example, in case of smart agriculture (in IoF2020), one interviewee clearly pointed out the importance of maturity of the IoT solutions when the farmers are expected to work with that:

"If the farmers get an immature technology even if it is free, they will be disappointed and then it will be very difficult to ask them to use it again. Farmers are sensitive about the functionality which means the technology should always work." (Expert 4)

Sometimes pilot users need to use their personal resources, like their phone to install an app, which creates a burden imposed on the pilot users. While IoT LSPs involve intense interaction between things and people, any collision could happen to the natural flow of how things flow around the pilot environment. The challenge with the LSPs was to cope with the burden caused by the pilot to the participants. This burden was related to any deviation from this natural flow (i.e., as if the pilot was not present) that deemed to be a barrier for user adoption. While this burden was considered as an 
adoption barrier for pilot users, the experts remarked upon in numerous quarters as it became difficult for LSPs to follow their plans.

In addition to accommodating user needs, time to learn new technology was found to be a major obstacle: "For a very practical reason, if it demands time to be spent by the user to learn how to use it, it will be a barrier" (Expert 7). The same expert also noted that a good design-ergonomic for physical products and visual for digital components-is needed to tackle barriers related to implementation. However, these two aspects are often pushed by the technology vendor and the LSP might have little control over them.

\subsection{Confirmation}

Confirmation in the context of an LSP means that users decide to use the technology throughout the pilot and beyond (if applicable) in the real life situations. Confirmation depends on various factors and stakeholders to become effective. For an individual end-user, the most important circumstance is a benefit received via the technology. Such a benefit could be individual, group and societal at large, depending on the application level of IoT. While focusing on the users was important for the pilots, other actors and stakeholders such as authorities, municipalities, event organizers and relevant communities needs to benefit as well at the end. In this regard, their lack of support could impact user's long-term perceived benefits.

"We lack ROI [Return of Investment] examples... The real challenge for us is to show to the cities the real impact of using all these infrastructures and technologies and how they can lead to better applications and services, reduction of cost and a more innovative ecosystem in the city. In the case of the citizen, they are consumers of the service or application ... at no additional cost. They only need a mobile phone." (Expert 9)

In most cases, cost of technology was relevant for the user adoption, especially for the individual and all-inclusive levels. In the case of MONICA project, the business model was planned in a sense that the cost would be hidden such that the users receive the wristband with the purchase of the concert ticket whereas in the case of smart elderly care (as mentioned in the workshop 1), the costs had to be paid by the elderly, municipalities or care takers. The cost was also related not only to the IoT acquisition but the costs that are reduced via the technology implementation. Since the cost is not important in a pilot study because users are only testing and evaluating, the confirmation for further adoption was based on focusing on what costs could be reduced via IoT, specifically for the infrastructural and organizational levels, as noted by two experts:

"At the end of the project we will do such analysis about the costs of the technology because the event organizers [users] always ask us how much it will cost if we want to use it after the project" (Expert 6).

"The user does not have the option to choose between the available services. The user pays indirectly for the car [either autonomous car or normal car] but not for the application that is used for example for car sharing service. So, the service itself is not payable but revenue is coming from another side (advertisement, tickets, etc.)" (Expert 2).

\section{Discussion}

The idea of things connected to other things and humans via the internet infrastructure proposes a future of new hyperconnected world which will impact the lives of many. Complex, scalable, cooperative work, true interoperability and ease of IoT deployment is a challenge for research and practice on one hand and adoption of IoT by its end-users and citizens on the other hand. In call for addressing such complex dynamics surrounding emerging IoT applications, the deployment of IoT large scale pilots have emerged in the recent years. In doing so, LSPs undergo a series of activities with various users and citizens. Therefore, we investigated IoT adoption barriers within LSPs from a process perspective. Utilizing Rogers' diffusion of innovation (DOI) theory, we stumbled upon some interesting theoretical insights.

First, the most interesting finding was that stages of innovation in Rogers' diffusion of innovation theory were not always linear in a context of a pilot study. While DOI has been the dominant paradigm 
in organizational innovation adoption studies, the LSPs did not seem to communicate their innovation in an orderly manner as suggested by DOI. Moreover, LSPs strived to push their technology wherever they found fit in the process of adoption (e.g., through interaction checkpoints) resulting in excluding or combining certain stages of the process. One explanation could be that the context of a pilot is perceived as an arena to test and evaluate innovation, whereas in an organizational context, adoption and diffusion of an innovation is the focus. The results reflect those of Straub [77] who argued that most of the stages are not clear cut in technology adoption theories.

Another justification could be attributed to the scope and underlying assumptions of DOI. The theory assumes a static, final form of the innovation. This assumption is challenged in the IoT LSP context for two reasons-(a) the digital components in IoT solutions makes them reconfigurable and dynamic which means barriers can keep changing and (b) the LSPs are still pilots, meaning that they test on a large scale and modify the solutions or at least learn from the pilots' interaction with the user. On the other hand, the scope covers the communication with the user while some barriers either have precursors in the design and development of the innovation or appear in the continued use and thus can be tackled in the wider innovation process. Examples of these barriers are the lack of trust, privacy and security and high cost of the technology. All these barriers would require tackling in a more holistic manner, across process phases and across levels (i.e., societal, organization and individual).

Second, collaborations in an LSP mean that a stakeholder assumes different roles when connected to other stakeholders-another reason why a linear view of adoption is challenged. For instance, an LSP consortium can be both a facilitator and a technology provider and a city can be both an infrastructure and a service provider. Similarly, the same stakeholder may have different users with varying levels of decision-making power when it comes to adopting or using the technology (i.e., referred to as individual and assimilation levels of adoption cf. [78]). In accordance with the present results, previous studies have demonstrated that individual and assimilation stages of adoption in the organizations are seldom parallel to the "stages" of individual adoption [79]. Our results show that the context of an LSP is different of an organizational context, in which individuals are part of the assimilation of complex innovations where individuals, groups, teams or departments are associated [69]. In the LSP, such associations are weak and sometimes there is no binding between different stakeholders, implying that this constellation requires a new understanding of users and end-users to better understand adoption processes. Even though adoption studies focus mainly on the individual level-like we did at the outset of this study, it is often problematic to exclude certain users if a holistic view of adoption is sought.

Third, while a body of knowledge suggests that co-creation facilitates innovation adoption [80,81], LSPs struggled to cope with the co-creation. On one hand high technology readiness level did not open much space for co-creation, on the other hand they were striving to make use of user feedback in their pilots. The situation created a dilemma-the idea behind an LSP is to allow to test in real settings and prepare for the wider IoT adoption [17], our result showed that failures in a pilot may induce a negative cycle of non-adoption [82]. To mitigate the situation, LSP tried to exert co-creation approaches, although the level of influence on the technology itself was limited, to understand their target groups and to reach out to them in order to compensate any potential technology failure.

Forth, as outlined by Rogers [9] in his DOI theory, each and every innovation has five attributes, namely, relative advantage, compatibility, complexity, trialability and observability. While some studies have considered these five attributes mainly connected to the persuasion phase $[83,84]$ our study showed that these characteristics might be linked and affect other phases of innovation adoption when it comes to IoT technologies in LSPs. For example, for an end-user, the complexity of the IoT sensors is directly linked to the implementation phase, when an end-user decides to use that IoT device in a limited basis. That is also the case for trialability of an innovation in which the LSPs give end-users this opportunity to use the innovation (i.e., implementation phase) regardless of their persuasion about the innovation. One plausible explanation for this is that DOI theory has widely been used within an organizational context $[85,86]$. Accordingly, an organization should first be persuaded 
about the complexity or trialability of the innovation and then a favorable decision towards using (i.e., in the implementation phase) the innovation within the organization is being made. In addition, as mentioned before, LSPs do not follow the process as it is, therefore end-users are faced with the technology in which might not had any knowledge of before and instead of a mental trial, they might already start with an actual trial. Consequently, the effects of previous steps on the later steps are not predictable in the case of an LSP.

In terms of study limitations, while the current study provides insights on the process of IoT adoption in the scope of LSPs and its inherent barriers, further research is needed to account for such barriers from an end-user perspective. Even though our experts and workshop participants represent different types of stakeholders within the LSPs, providing us with a holistic view of all respective user types, involving these end-users and the adoption barriers as they experience themselves is undoubtedly to reveal unique barriers and mental processes. Moreover, developing a multi-layered theory of diffusion would help extend the analysis between different layers in a complex and multi-stakeholder environment such as an LSP. Furthermore, it would be interesting to extend the study results to other relevant domains such as industrial IoT applications, consumer and home based IoT solutions in order to explore the similarities between the barriers found in an LSP compared to that of industrial and consumer based IoT.

\section{Conclusions}

The European IoT Large-Scale Pilots (LSP) program is an initiative from the European Commission to foster the integration, deployment and testing of IoT solutions from reduced and controlled environments into to real-life use case scenarios. One aim of LSPs is to nurture the end-user acceptance and adoption of IoT solutions. This study set out to investigate the process of end-user adoption of IoT within LSPs and subsequent factors that hinders adoption. By examining four European LSPs in four application domains of IoT, we identified relevant adoption barriers in each domain. Additionally, using the Diffusion of Innovation theory [9], our findings suggest that the process of adoption in the context of an LSP is not orderly, which is in contrast with the theory. One plausible explanation is that projects seek any opportunity for test and evaluation of their artefact by end-users. As opposed to adoption of technology in organizations where institutional properties guide the adoption process, in an LSP, the adoption does not follow an order and adoption stages are combined, interrupted and transposed. Moreover, we found that the IoT artefact itself, contextual factors and types of end-users led LSPs to adjust their strategies to diffuse their innovation. The findings of this study have several important implications for future practice that can assist future IoT LSPs in facilitating end-user adoption of their products and services. Below, we have compiled our suggestions and those given by the experts who participated in this study:

- Developing suitable inclusive strategies for awareness-Since LSPs work with new solutions to their respective markets, they need to develop strategies for how they will create awareness around their solutions, both in terms of knowing about them as well as their features and added value. Suitable strategies imply using the right channels, right messages and be inclusive of different user types.

- Involve users early on in the process-Involving the users in early testing promotes trust and increases transparency in the developed solutions. Since technology immaturity also acts as a barrier in this context, managing expectations and effective co-creation strategies are needed to navigate this space.

- Continuously address privacy and security issues-From conception, design to implementation and continued use of the solution, there are privacy concerns to be addressed. Practices that LSPs could follow, among others, include communicating about type of collected data, opt-in/opt-out options over collection, storage and use of the information, privacy by design, trusted third-party badges and compliance with regulations (e.g., GDPR), can greatly decrease individual's privacy concern. 
- Focus on the added value-Whether this is in terms of ROI for a business user or an emotional/hedonic value for an individual user, this value needs to be highlighted and contextualized so that the user can relate to it. Concrete examples and relating to their existing reality are often helpful to persuade them of such value.

- On the importance of design-With IoT solutions, design includes physical features of physical products (e.g., ergonomic) as well as design of associated digital services. A good design will help with users' trust, promote transparency, is easy to learn and use and enable continued use after adoption.

- Engaging in ecosystem development-Even if all barriers are tackled, some ecosystem-bound barriers are still in place. These include, for example, the legal framework around a new technology or standardization efforts.

Author Contributions: All authors conceived the idea. A.P. and A.R. conducted the literature reviews. A.H. and A.P. conducted the expert interviews. A.H. conducted two workshops and contributed to the theoretical framework. A.P., A.H., A.R. and A.S. analyzed the data. A.P., A.H. and A.R. drafted the manuscript jointly. All authors have read and agreed to the published version of the manuscript.

Funding: This work was funded by the European Commission in the context of the Horizon 2020 project U4IoT (Grant Agreement No. 732078).

Acknowledgments: Parts of the literature study have been included in an earlier version of a deliverable submitted by the authors to the U4IoT project. The authors would like to thank Wim Vanobberghen for his contribution to conducting the interviews and the LSP representatives for providing their expertise.

Conflicts of Interest: The authors declare no conflict of interest.

\section{Appendix A}

In structuring the study, an interview protocol based on a set of questions derived from DOI was followed. The interview started from some general questions regarding the experiences of the participants, their role in the project and a brief overview of the tasks they were involved with. After this, the participants were given a definition of each phase of DOI, followed by questions regarding that phase. The questions are presented as below:

\section{Grand tour questions}

- From an overarching view, what do you think of as the main barriers for a typical person to adopt and start using IoT solutions in [smart cities, smart agriculture, wearable technologies, smart home care and autonomous driving vehicles]?

- From an overall perspective, what are your recommendations and suggestions to tackle the barriers that you mentioned in the previous question?

\section{Regarding each phase in DOI (repeated for each phase)}

- From the insights of the pilots and the project, what came out as the main barriers in the [knowledge, Persuasion, Decision, Implementation and Confirmation], phase for end-users to adopt IoT solutions in [smart cities, smart agriculture, wearable technologies, smart home care and autonomous driving vehicles]?

- What do you recommend in order to tackle IoT adoption barriers that you just mentioned with respect to the end-users of the IoT solutions?

\section{Wrap up}

- Do you feel or experience, that there are any other barriers that might influence your willingness to start using IoT solutions? Which might that be? Please explain.

- Do you have any other suggestions or recommendations in order to tackle IoT adoption barriers for end-users? Please explain. 
- Is there anything else you would like to add to this interview? Anything that you would like us to know or anything that you would like the developers of this type of technologies to think of?

\section{References}

1. Gubbi, J.; Buyya, R.; Marusic, S.; Palaniswami, M. Internet of Things (IoT): A vision, architectural elements, and future directions. Future Gener. Comput. Syst. 2013, 29, 1645-1660. [CrossRef]

2. Kim, J.H.; Yoo, M.; Lee, K.N.; Seo, H. The innovation of the internet: A semantic network analysis of the Internet of Things. Asian J. Technol. Innov. 2017, 25, 129-139. [CrossRef]

3. Kreps, D.; Kimppa, K. Theorising Web 3.0: ICTs in a changing society. Inf. Technol. People 2015, 28, 726-741. [CrossRef]

4. Falcone, R.; Sapienza, A. On the Users' Acceptance of IoT Systems: A Theoretical Approach. Information 2018, 9, 53. [CrossRef]

5. Gao, L.; Bai, X. A unified perspective on the factors influencing consumer acceptance of internet of things technology. Asia Pac. J. Mark. Logist. 2014, 26, 211-231. [CrossRef]

6. Habibipour, A.; Padyab, A.; Bergvall-Kåreborn, B.; Ståhlbröst, A. Exploring Factors Influencing Participant Drop-Out Behavior in a Living Lab Environment; Springer: Cham, Switzerland, 2017; pp. $28-40$.

7. Lu, Y.; Papagiannidis, S.; Alamanos, E. Internet of Things: A systematic review of the business literature from the user and organisational perspectives. Technol. Forecast. Soc. Chang. 2018, 136, 285-297. [CrossRef]

8. Davis, F.D. Perceived usefulness, perceived ease of use, and user acceptance of information technology. MIS Q. 1989, 13, 319-340. [CrossRef]

9. Rogers, E.M. Diffusion of Innovations, 4th ed.; Simon and Schuster: New York, NY, USA, 2010; ISBN 978-1-4516-0247-0.

10. Ammirato, S.; Sofo, F.; Felicetti, A.M.; Raso, C. A methodology to support the adoption of IoT innovation and its application to the Italian bank branch security context. Eur. J. Innov. Manag. 2018, 22, 146-174. [CrossRef]

11. Wisdom, J.P.; Chor, K.H.B.; Hoagwood, K.E.; Horwitz, S.M. Innovation Adoption: A Review of Theories and Constructs. Adm. Policy Ment. Health Ment. Health Serv. Res. 2014, 41, 480-502. [CrossRef]

12. ISO 9241-210:2010. Available online: http:/www.iso.org/cms/render/live/en/sites/isoorg/contents/data/ standard/05/20/52075.html (accessed on 30 April 2019).

13. Nesrin, A.; Georg, A.; Mario, D.; Maria, F.K.; Christopher, F.; Markus, G.; Manfred, K.; Daniela, K.; Johannes, K.; Kurt, M.; et al. Assistive solutions in practice: Experiences from AAL pilot regions in Austria. Stud. Health Technol. Inform. 2017, 236, 184.

14. Lee, I.; Lee, K. The Internet of Things (IoT): Applications, investments, and challenges for enterprises. Bus. Horiz. 2015, 58, 431-440. [CrossRef]

15. Brewster, C.; Roussaki, I.; Kalatzis, N.; Doolin, K.; Ellis, K. IoT in Agriculture: Designing a Europe-Wide Large-Scale Pilot. IEEE Commun. Mag. 2017, 55, 26-33. [CrossRef]

16. Friess, P.; Riemenschneider, R. New Horizons for the Internet of Things in Europe. In Building the Hyperconnected Society: IoT Research and Innovation Value Chains, Ecosystems and Markets; Vermesan, O., Friess, P., Eds.; River Publishers: Aalborg, Denmark, 2015; pp. 5-13.

17. Vermesan, O.; Friess, P. AIOTI WG01: Report on Internet of Things Applications. Available online: https:/aioti.eu/aioti-wg01-report-on-internet-of-things-applications/ (accessed on 2 May 2019).

18. Sanchez, L.; Muñoz, L.; Galache, J.A.; Sotres, P.; Santana, J.R.; Gutierrez, V.; Ramdhany, R.; Gluhak, A.; Krco, S.; Theodoridis, E.; et al. SmartSantander: IoT experimentation over a smart city testbed. Comput. Netw. 2014, 61, 217-238. [CrossRef]

19. Vermesan, O.; Friess, P.; Guillemin, P.; Giaffreda, R.; Grindvoll, H.; Eisenhauer, M.; Serrano, M.; Moessner, K.; Spirito, M.; Blystad, L.-C. Internet of things beyond the Hype: Research, Innovation and Deployment. In Building the Hyperconnected Society: IoT Research and Innovation Value Chains, Ecosystems and Markets; Vermesan, O., Friess, P., Eds.; River Publishers: Aalborg, Denmark, 2015; pp. 15-118.

20. Fico, G.; Montalva, J.-B.; Medrano, A.; Liappas, N.; Mata-Díaz, A.; Cea, G.; Arredondo, M.T. Co-creating with consumers and stakeholders to understand the benefit of Internet of Things in Smart Living Environments for Ageing Well: The approach adopted in the Madrid Deployment Site of the ACTIVAGE Large Scale Pilot. In EMBEC \& NBC 2017; Eskola, H., Väisänen, O., Viik, J., Hyttinen, J., Eds.; Springer: Singapore, 2018; pp. 1089-1092. ISBN 978-981-10-5121-0. 
21. Vermesan, O.; Eisenhauer, M.; Sundmaeker, H.; Guillemin, P.; Serrano, M.; Tragos, E.Z.; Valino, J.; van der Wees, A.; Gluhak, A.; Bahr, R. Internet of Things Cogitive Transformation Technology Research Trends and Applications. In Cognitive Hyperconnected Digital Transformation; Vermesan, O., Bacquet, J., Eds.; River Publishers: Delft, The Netherlands, 2017; pp. 17-95. ISBN 978-87-93609-11-2.

22. Khasawneh, A.M. Concepts and measurements of innovativeness: The case of information and communication technologies. Int. J. Arab Cult. Manag. Sustain. Dev. 2008, 1, 23-33. [CrossRef]

23. Damanpour, F.; Schneider, M. Phases of the Adoption of Innovation in Organizations: Effects of Environment, Organization and Top Managers1. Br. J. Manag. 2006, 17, 215-236. [CrossRef]

24. De Vries, H.; Bekkers, V.; Tummers, L. Innovation in the public sector: A systematic review and future research agenda. Public Adm. 2016, 94, 146-166. [CrossRef]

25. Padyab, A.; Ståhlbröst, A. Exploring the dimensions of individual privacy concerns in relation to the Internet of Things use situations. Digit. Policy Regul. Gov. 2018, 20, 528-544. [CrossRef]

26. Kayhan, V.O.; Davis, C.J. Situational Privacy Concerns and Antecedent Factors. J. Comput. Inf. Syst. 2016, 56, 228-237. [CrossRef]

27. Webster, J.; Watson, R.T. Analyzing the past to prepare for the future: Writing a literature review. MIS Q. 2002, 26, 13-23.

28. Curry, E.; Dustdar, S.; Sheng, Q.Z.; Sheth, A. Smart cities-Enabling services and applications. J. Internet Serv. Appl. 2016, 7, 6. [CrossRef]

29. Lytras, M.D.; Visvizi, A. Who uses smart city services and what to make of it: Toward interdisciplinary smart cities research. Sustainability 2018, 10, 1998. [CrossRef]

30. Perera, C.; Zaslavsky, A.; Christen, P.; Georgakopoulos, D. Sensing as a service model for smart cities supported by Internet of Things. Trans. Emerg. Telecommun. Technol. 2014, 25, 81-93. [CrossRef]

31. Pöhls, H.C.; Angelakis, V.; Suppan, S.; Fischer, K.; Oikonomou, G.; Tragos, E.Z.; Mouroutis, T. RERUM: Building a reliable IoT upon privacy- and security- enabled smart objects. In Proceedings of the 2014 IEEE Wireless Communications and Networking Conference Workshops (WCNCW), Istanbul, Turkey, 6-9 April 2014; pp. 122-127.

32. Ståhlbröst, A.; Padyab, A.; Sällström, A.; Hollosi, D. Design of Smart City Systems from a Privacy Perspective. IADIS Int. J. WWWInternet 2015, 13, 1-16.

33. Ok, A.E.; Basoglu, N.A.; Daim, T. Exploring the design factors of smart glasses. In Proceedings of the 2015 Portland International Conference on Management of Engineering and Technology (PICMET), Portland, OR, USA, 2-6 August 2015; pp. 1657-1664.

34. Duval, S.; Hashizume, H. Perception of Wearable Computers for Everyday Life by the General Public: Impact of Culture and Gender on Technology. In Embedded and Ubiquitous Computing_EUC 2005; Yang, L.T., Amamiya, M., Liu, Z., Guo, M., Rammig, F.J., Eds.; Springer: Berlin/Heidelberg, Germany, 2005; pp. 826-835.

35. Hein, D.W.E.; Rauschnabel, P.A. Augmented Reality Smart Glasses and Knowledge Management: A Conceptual Framework for Enterprise Social Networks. In Enterprise Social Networks: Erfolgsfaktoren für die Einführung und Nutzung_Grundlagen, Praxislösungen, Fallbeispiele; Rossmann, A., Stei, G., Besch, M., Eds.; Springer Fachmedien Wiesbaden: Wiesbaden, Germany, 2016; pp. 83-109. ISBN 978-3-658-12652-0.

36. Rauschnabel, P.A.; Brem, A.; Ivens, B.S. Who will buy smart glasses? Empirical results of two pre-market-entry studies on the role of personality in individual awareness and intended adoption of Google Glass wearables. Comput. Hum. Behav. 2015, 49, 635-647. [CrossRef]

37. Sivathanu, B. Adoption of internet of things (IOT) based wearables for healthcare of older adults-A behavioural reasoning theory (BRT) approach. J. Enabling Technol. 2018, 12, 169-185. [CrossRef]

38. Mann, S. An historical account of the "WearComp" and "WearCam" inventions developed for applications in "personal imaging". In Proceedings of the Digest of Papers. First International Symposium on Wearable Computers, Cambridge, MA, USA, 13-14 October 1997; pp. 66-73.

39. Kim, K.J.; Shin, D.-H. An acceptance model for smart watches: Implications for the adoption of future wearable technology. Internet Res. 2015, 25, 527-541. [CrossRef]

40. Collins, T. Mysterious Burn-Like Marks Caused by Samsung's Gear Fit2 Smart Watch. Available online: http://www.dailymail.co.uk/ \{\}/article-4364762/index.html (accessed on 15 March 2019).

41. Stock, B.; dos Santos Ferreira, T.P.; Ernst, C.-P.H. Does Perceived Health Risk Influence Smartglasses Usage? In The Drivers of Wearable Device Usage: Practice and Perspectives; Ernst, C.-P.H., Ed.; Progress in IS; Springer International Publishing: Cham, Switzerland, 2016; pp. 13-23. ISBN 978-3-319-30376-5. 
42. Pustiek, M.; Beristain, A.; Kos, A. Challenges in Wearable Devices Based Pervasive Wellbeing Monitoring. In Proceedings of the 2015 International Conference on Identification, Information, and Knowledge in the Internet of Things (IIKI), Beijing, China, 22-23 October 2015; pp. 236-243.

43. Jung, Y.; Kim, S.; Choi, B. Consumer valuation of the wearables: The case of smartwatches. Comput. Hum. Behav. 2016, 63, 899-905. [CrossRef]

44. Cain, P. Unlock the full potential of wearables with organic TFTs. Inf. Disp. 2015, 31, 22-26. [CrossRef]

45. Billinghurst, M.; Starner, T. Wearable devices: New ways to manage information. Computer 1999, 32, 57-64. [CrossRef]

46. Adapa, A.; Nah, F.F.-H.; Hall, R.H.; Siau, K.; Smith, S.N. Factors Influencing the Adoption of Smart Wearable Devices. Int. J. Hum. Comput. Interact. 2018, 34, 399-409. [CrossRef]

47. Firouzi, F.; Farahani, B.; Ibrahim, M.; Chakrabarty, K. Keynote Paper: From EDA to IoT eHealth: Promises, Challenges, and Solutions. IEEE Trans. Comput. Aided Des. Integr. Circuits Syst. 2018, 37, 2965-2978. [CrossRef]

48. Habibipour, A.; Padyab, A.; Ståhlbröst, A. Social, Ethical and Ecological Issues in Wearable Technologies. In Proceedings of the AMCIS 2019, Twenty-Fifth Americas Conference on Information Systems, Cancun, México, 15-17 August 2019; pp. 1-10.

49. Lee, J.D.; See, K.A. Trust in Automation: Designing for Appropriate Reliance. Hum. Factors 2004, 46, 50-80. [CrossRef]

50. Morgan, P.L.; Williams, C.; Flower, J.; Alford, C.; Parkin, J. Trust in an Autonomously Driven Simulator and Vehicle Performing Maneuvers at a T-Junction with and Without Other Vehicles. In Advances in Human Aspects of Transportation, Stanton; Stanton, N., Ed.; Springer International Publishing: Cham, Switzerland, 2019; pp. 363-375.

51. Fraedrich, E.; Lenz, B. Taking a Drive, Hitching a Ride: Autonomous Driving and Car Usage. In Autonomous Driving: Technical, Legal and Social Aspects; Maurer, M., Gerdes, J.C., Lenz, B., Winner, H., Eds.; Springer: Berlin/Heidelberg, Germany, 2016; pp. 665-685. ISBN 978-3-662-48847-8.

52. Fraedrich, E.; Lenz, B. Societal and Individual Acceptance of Autonomous Driving. In Autonomous Driving: Technical, Legal and Social Aspects; Maurer, M., Gerdes, J.C., Lenz, B., Winner, H., Eds.; Springer: Berlin/Heidelberg, Germany, 2016; pp. 621-640. ISBN 978-3-662-48847-8.

53. Zmud, J.P.; Sener, I.N. Towards an understanding of the travel behavior impact of autonomous vehicles. Transp. Res. Procedia 2017, 25, 2500-2519. [CrossRef]

54. Fagnant, D.J.; Kockelman, K. Preparing a nation for autonomous vehicles: Opportunities, barriers and policy recommendations. Transp. Res. Part Policy Pract. 2015, 77, 167-181. [CrossRef]

55. Levin, M.W.; Boyles, S.D. Effects of autonomous vehicle ownership on trip, mode, and route choice. Transp. Research Rec. J. Transp. Res. Board 2015, 2493, 29-38. [CrossRef]

56. Kazemi, M.; Panikulam, J.; Liu, C.; Lee, A.; Bradley, D.M.; Hogg, C.R., III. Automatic Tuning of Autonomous Vehicle Cost Functions Based on Human Driving Data. U.S. Patent Application No. 15/607,994, 11 October 2018.

57. Sun, X.; Lin, W.; Liu, L.; Ma, K.-C.; Xuan, Z.; Zhao, Y. System and Method for Autonomous Vehicle Control to Minimize Energy Cost. U.S. Patent Application No. 15/685,715, 28 February 2019.

58. Tafti, S.R.J.; Zou, G.J.; Huber, M.J.; Mudalige, U.P. Trajectory Planner with Dynamic Cost Learning for Autonomous Driving. U.S. Patent Application No. 15/859,857, 7 July 2019.

59. Madushanki, A.A.R.; Halgamuge, M.N.; Wirasagoda, W.A.H.S.; Syed, A. Adoption of the Internet of Things (IoT) in Agriculture and Smart Farming towards Urban Greening: A Review. Int. J. Adv. Comput. Sci. Appl. 2019, 10, 11-28. [CrossRef]

60. Jayashankar, P.; Nilakanta, S.; Johnston, W.J.; Gill, P.; Burres, R. IoT adoption in agriculture: The role of trust, perceived value and risk. J. Bus. Ind. Mark. 2018, 33, 804-821. [CrossRef]

61. Lin, D.; Lee, C.K.M.; Tai, W.C. Application of Interpretive Structural Modelling for Analyzing the Factors of IoT Adoption on Supply Chains in the Chinese Agricultural Industry. In Proceedings of the 2017 IEEE International Conference on Industrial Engineering and Engineering Management (IEEM), Singapore, 10-13 December 2017; IEEE: New York, NY, USA, 2017; pp. 1347-1351, ISBN 978-1-5386-0948-4.

62. Kautsarina; Kusumawati, D. The Potential Adoption of the Internet of Things in Rural Areas; Kusumawati, D., Nugroho, B.A., Ruth, E.S.E., Eds.; IEEE: New York, NY, USA, 2018; ISBN 978-1-5386-7781-0. 
63. Lin, D.; Lee, C.K.M.; Lin, K. Research on Effect Factors Evaluation of Internet of Things (IOT) Adoption in Chinese Agricultural Supply Chain; IEEE: New York, NY, USA, 2016; ISBN 978-1-5090-3665-3.

64. Mylonas, P.; Voutos, Y.; Sofou, A. A Collaborative pilot platform for data annotation and enrichment in viticulture. Information 2019, 10, 149. [CrossRef]

65. Vasisht, D.; Kapetanovic, Z.; Won, J.; Jin, X.; Chandra, R.; Sinha, S.; Kapoor, A.; Sudarshan, M.; Stratman, S. FarmBeats: An IoT Platform for Data-Driven Agriculture. In Proceedings of the 14th \{USENIX\} Symposium on Networked Systems Design and Implementation (\{NSDI\} 17), Boston, MA, USA, 27-29 March 2017; pp. 515-529.

66. Ramundo, L.; Taisch, M.; Terzi, S. State of the art of technology in the food sector value chain towards the IoT. In Proceedings of the 2016 IEEE 2nd International Forum on Research and Technologies for Society and Industry Leveraging a better tomorrow (RTSI), Bologna, Italy, 7-9 September 2016; pp. 1-6.

67. Tu, M. An exploratory study of Internet of Things (IoT) adoption intention in logistics and supply chain management: A mixed research approach. Int. J. Logist. Manag. 2018, 29, 131-151. [CrossRef]

68. Lyytinen, K.; Damsgaard, J. What's Wrong with the Diffusion of Innovation Theory? In Diffusing Software Product and Process Innovations; Ardis, M.A., Marcolin, B.L., Eds.; Springer US: Boston, MA, USA, 2001; pp. 173-190.

69. Meyer, A.D.; Goes, J.B. Organizational assimilation of innovations: A multilevel contextual analysis. Acad. Manag. J. 1988, 31, 897-923.

70. Benbasat, I.; Goldstein, D.K.; Mead, M. The case research strategy in studies of information systems. MIS Q. 1987, 11, 369-386. [CrossRef]

71. Yin, R.K. Case Study Research: Design and Methods, 4th ed.; SAGE Publications, Inc.: Los Angeles, CA, USA, 2008; ISBN 978-1-4129-6099-1.

72. Schultze, U.; Avital, M. Designing interviews to generate rich data for information systems research. Inf. Organ. 2011, 21, 1-16. [CrossRef]

73. Mayring, P. Qualitative content analysis—research instrument or mode of interpretation? In The Role of the Researcher in Qualitative Psychology; Kiegelmann, M., Ed.; Huber: Tübingen, Germany, 2000; pp. 139-148.

74. Wainwright, M.; Russell, A. Using NVivo audio-coding: Practical, sensorial and epistemological considerations. Soc. Res. Update 2010, 1-4.

75. Lincoln, Y.S.; Guba, E.G. Naturalistic Inquiry; SAGE Publications: Newbury Park, CA, USA, 1985; ISBN 978-0-8039-2431-4.

76. Tong, A.; Sainsbury, P.; Craig, J. Consolidated criteria for reporting qualitative research (COREQ): A 32-item checklist for interviews and focus groups. Int. J. Qual. Health Care 2007, 19, 349-357. [CrossRef] [PubMed]

77. Straub, E.T. Understanding Technology Adoption: Theory and Future Directions for Informal Learning. Rev. Educ. Res. 2009, 79, 625-649. [CrossRef]

78. Greenhalgh, T.; Robert, G.; Macfarlane, F.; Bate, P.; Kyriakidou, O. Diffusion of Innovations in Service Organizations: Systematic Review and Recommendations. Milbank Q. 2004, 82, 581-629. [CrossRef] [PubMed]

79. Van de Ven, A.H.; Angle, H.L. The Innovation Journey; Oxford University Press: Oxford, UK, 1989.

80. Chesbrough, H. Open innovation: A new paradigm for understanding industrial innovation. In Open Innovation: Researching A New Paradigm; Chesbrough, H., Vanhaverbeke, W., West, J., Eds.; Oxford University Press: Oxford, UK, 2006; pp. 1-12.

81. Ramaswamy, V. Leading the transformation to co-creation of value. Strategy Leadersh. 2009, 37, 32-37. [CrossRef]

82. De Vries, P.; Midden, C.; Bouwhuis, D. The effects of errors on system trust, self-confidence, and the allocation of control in route planning. Int. J. Hum. Comput. Stud. 2003, 58, 719-735. [CrossRef]

83. Eagle, K.A.; Gallogly, M.; Mehta, R.H.; Baker, P.L.; Blount, A.; Freundl, M.; Orza, M.J.; Parrish, R.; Riba, A.L.; Montoye, C.K. Taking the National Guideline for Care of Acute Myocardial Infarction to the Bedside: Developing the Guideline Applied in Practice (GAP) Initiative in southeast Michigan. Jt. Comm. J. Qual. Improv. 2002, 28, 5-19. [CrossRef]

84. Johnson, K.K.P.; Lennon, S.J.; Jasper, C.; Damhorst, M.L.; Lakner, H.B. An Application of Rogers's Innovation Model: Use of the Internet to Purchase Apparel, Food, and Home Furnishing Products by Small Community Consumers. Cloth. Text. Res. J. 2003, 21, 185-196. [CrossRef] 
85. HAIDER, M.; KREPS, G.L. Forty Years of Diffusion of Innovations: Utility and Value in Public Health. J. Health Commun. 2004, 9, 3-11. [CrossRef] [PubMed]

86. Hameed, M.A.; Counsell, S.; Swift, S. A conceptual model for the process of IT innovation adoption in organizations. J. Eng. Technol. Manag. 2012, 29, 358-390. [CrossRef] 